\title{
THE SPEED OF HEALING AFTER FRACTURE OF THE TIBIAL SHAFT *
}

\author{
H. Ellis, Oxford, ENGland \\ From the Royal Infirmary, Sheffield
}

Although there is a considerable literature on possible factors concerned in the speed of fracture healing, surprisingly few controlled clinical studies have been carried out to assess their importance. Such investigations are only valid when fractures are compared which differ solely in the particular variable under consideration; any significant difference in the speed of union between two such groups can then be attributed entirely to this factor.

The present study attempts to investigate the effects of certain factors-particularly severity of injury, skeletal traction and distraction-on fracture healing, using this technique in a consecutive series of tibial shaft fractures.

\section{CLINICAL MATERIAL, CLASSIFICATION AND OBSERVATIONS}

During the six-year period 1948 to 1953,576 freshly sustained fractures of the tibial shaft were admitted to the Royal Infirmary, Sheffield (567 patients). Of these fractures, 535 were available for the study of primary fracture healing in normal bone. Nine others, to be considered separately, were treated by bone grafting for delayed union or non-union. The remaining thirty-two fractures comprised those necessitating immediate amputation, pathological fractures and fatalities from overwhelming injuries.

A preliminary survey revealed invariable and rapid healing of tibial fractures in patients under the age of sixteen years; in no instance in this group was immobilisation required for more than twelve weeks. The patients have, therefore, been divided by this arbitrary figure of 16 into children (192 fractures) and adults ( 343 fractures), the main study being concentrated on the adult group.

TABLE I

Speed of Union and Incidence of Delayed Union in Fractures Classified According to Severity of InJURY

\begin{tabular}{|lccc|}
\hline $\begin{array}{l}\text { Severity of } \\
\text { injury }\end{array}$ & $\begin{array}{c}\text { Number of } \\
\text { fractures }\end{array}$ & $\begin{array}{c}\text { Average time } \\
\text { of union } \\
\text { (weeks) }\end{array}$ & $\begin{array}{c}\text { Cases of } \\
\text { delayed union } \\
\text { (more than 20 weeks) }\end{array}$ \\
\hline Minor & 98 & 10 & $2 \dagger(2 \%)$ \\
Moderate & 200 & 15 & $22(11 \%)$ \\
Major & 45 & 23 & $27(60 \%)$ \\
\hline Total & 343 & & \\
\hline
\end{tabular}

$\dagger$ This includes one fracture for which prolonged immobilisation was required because of an associated major fracture of the femur in the same limb.

The fractures in adults fall into three groups according to the treatment employed: 1) 222 fractures were treated by immobilisation only; 2) 112 longitudinally unstable fractures were treated by plaster immobilisation supplemented by skeletal traction through the calcaneum; 3) nine unstable fractures were treated by fixation with one or more screws together with plaster immobilisation.

* Being part of the substance of a thesis accepted for the degree of M.Ch.(Oxon). 
The severity of the initial injury-Three variables were used in this study to assess severity of tissue trauma-namely, the degree of fracture displacement, the extent of the compound wound and the severity of comminution.

In a detailed investigation of this series of fractures (Ellis 1956) it was found that minor degrees of compound wounding or of comminution had no demonstrable effect on the speed of union; the rate of healing of such fractures did not differ from that of otherwise similar, but closed and non-comminuted fractures. The three factors which did delay healing in a statistically significant manner were complete displacement, severe compound wounding and severe comminution. In effect, the average time required for union of the most severe fractures was more than twice that of the relatively minor injuries, as will be detailed later.

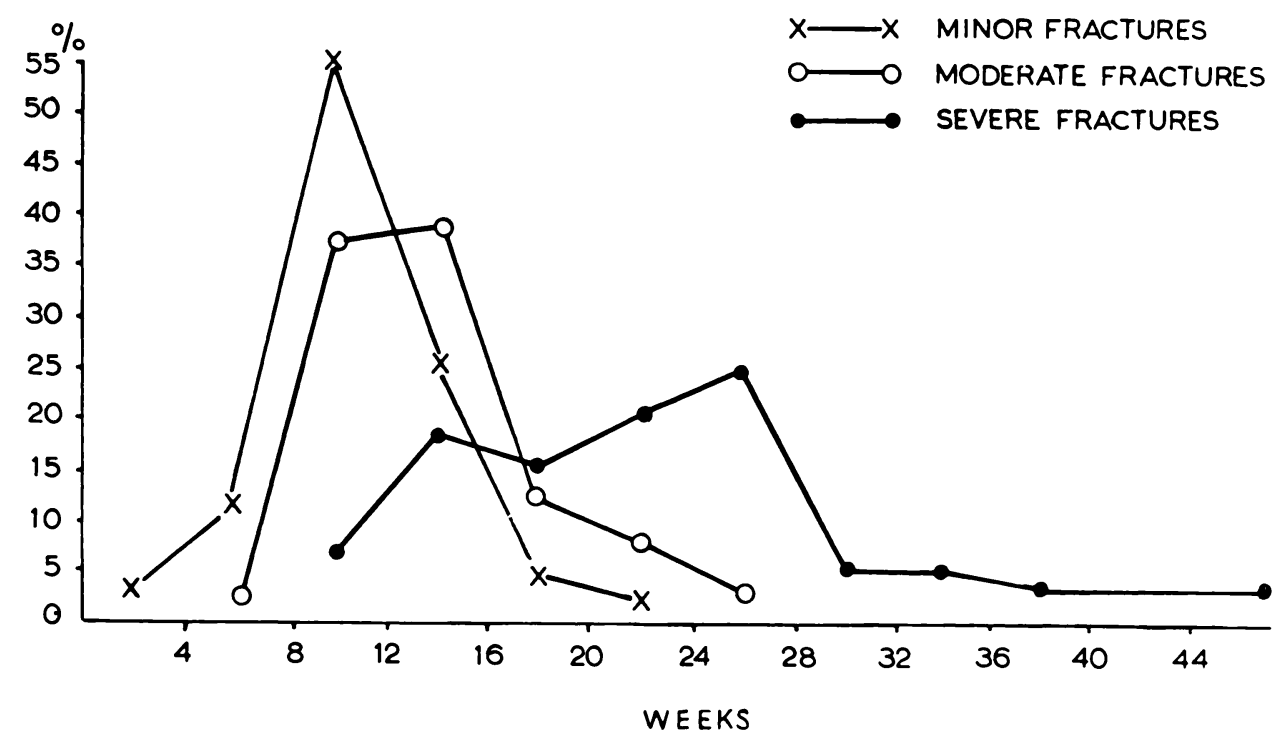

FIG. 1

Histogram demonstrating the rates of union of tibial shaft fractures of minor, moderate and major severity. The percentage of fractures that were united at the end of each four-week period is shown for each group.

These findings have been combined to enunciate a simple classification of fractures into three groups of severity, defined as follows: 1) Minor severity-fractures with undisplaced or angulated fragments, whether or not complicated by minor degrees of comminution or compound wounding. 2) Moderate severity - fractures with completely displaced fragments, whether or not complicated by minor degrees of comminution or compound wounding. 3) Major severity - fractures complicated by major comminution or a major compound wound. (In practice these were all found to be completely displaced.)

Table I shows the average time of union* and the incidence of delayed union $\dagger$ in these three grades of severity of injury, the average times being ten, fifteen and twenty-three weeks respectively and incidence of delayed union 2 per cent, 11 per cent and 60 per cent respectively $(\mathrm{P}=<0 \cdot 01)$. These differences are illustrated by the histogram (Fig. 1) which demonstrates

* Clinical union is said to have occurred when pressure over the fracture and "springing" the bone failed to elicit pain. Naturally, this measurement allows wide variations. However, all the patients were treated under the supervison of one consultant and a small number of registrars, so that a relatively constant level of assessment may be considered to have existed.

$\dagger$ Delayed union is said to have taken place when clinical union of the fracture occurred after more than twenty weeks' immobilisation.

VOL. $40 \mathrm{~B}$, NO. 1, FEBRUARY 1958 
the certain and rapid healing of minor fractures, the increasing scatter and delay in moderate fractures, and the marked shift to the right of the chart in fractures of major severity.

Now let us consider other factors which may affect the speed of fracture union, using this classification as a means of providing groups of fractures of comparable severity of tissue trauma.

Infection occurred in five of the 105 compound fractures which proceeded to clinical union. The numbers are too small to be significant, but bone healing took place within the same limits of time as non-infected fractures of comparable severity treated by similar methods. Certainly, infection alone could not account for the delays in healing of major compound fractures in the present study.

Distraction (defined as a gap of one-sixteenth of an inch or more between the fragments, measured on the radiograph after reduction) was present in eighteen of the 112 fractures treated by skeletal traction (16 per cent.) Distracted fractures took, on the average, five

TABLE II

Comparison Between Rates of Union of Distracted and Non-distracted Fractures of Comparable Severity Treated by Skeletal Traction

\begin{tabular}{|lccc|}
\hline $\begin{array}{c}\text { Severity of } \\
\text { injury }\end{array}$ & $\begin{array}{c}\text { Number of } \\
\text { fractures }\end{array}$ & $\begin{array}{c}\text { Average time } \\
\text { of union (weeks) }\end{array}$ & $\begin{array}{c}\text { Delayed union } \\
\text { (more than 20 weeks) }\end{array}$ \\
\hline Moderate & 13 & 19 & $6 \quad(46 \%)$ \\
Distracted & 74 & 14 & $6 \quad(8 \%)$ \\
Not distracted & 5 & 30 & $5 \quad(100 \%)$ \\
Major & 19 & 25 & $11 \quad(58 \%)$ \\
Distracted & $111^{*}$ & & \\
\hline Not distracted & & & \\
\hline Total & & & \\
\hline
\end{tabular}

* One fracture excluded because no immediate post-reduction radiographs are available.

weeks longer to unite than comparable fractures treated by traction without distraction $(\mathrm{P}=<0.01)$. The risk of delayed union was also considerably increased (Table II).

Traction-To assess whether skeletal traction, in which distraction has been avoided, affects the speed of union, I compared fractures treated by plaster immobilisation alone with cases of comparable severity treated by calcaneal traction, excluding cases with distraction (Table III). There was no significant difference between comparable fractures of moderate severity treated by these methods $(P=0 \cdot 35)$. In major fractures, although the incidence of delayed union was comparable, there was a lag (five weeks) in the average rate of healing in the cases treated by traction $(\mathrm{P}=<0.01) \cdot \dagger$

Age of the patient-It has already been noted that tibial fractures in patients under the age of sixteen united with uniform rapidity. Above this age, no statistical difference existed between the various age groups, providing fractures of comparable severity were studied.

Site of fracture-With one exception, fractures of comparable severity at various sites of the

† One should note that this difference was due to two fractures with extremely severe tissue damage included in the traction group. Both were initially borderline cases for immediate amputation, both were subject to marked delay in healing (fifty and fifty-six weeks) and both were without equivalent in the cases treated by immobilisation only. If these two cases are allowed for, there was an average lag of two weeks in the major fractures treated by traction compared with similar fractures treated by immobilisation, there being no statistical difference between the two groups $(P=0 \cdot 65)$. 
tibial shaft showed no significant difference in speed of union. This exception occurred in fractures immediately below the tibial condyles; only fractures of minor or moderate severity occurred at this site, but these united without a single example of delayed healing.

Fractures with delayed or non-union treated by bone grafting-Of the five fractures with established non-union in the series, two had been treated by traction and three by immobilisation alone. Of four fractures with delayed union treated by bone grafting. two had been subjected to traction (one revealing radiological evidence of distraction) and two to immobilisation alone. Of these nine fractures, no less than eight were injuries of major severity. The remaining one, a moderate fracture with established non-union, was found at operation to have muscle interposed between the fragments.

TABLE III

Comparison Between Rates of Union in Fractures of Comparable Severity Treated by ImMobilisation ONLy aNd ImMobilisation Supplemented by SKeletal Traction (Distracted cases excluded)

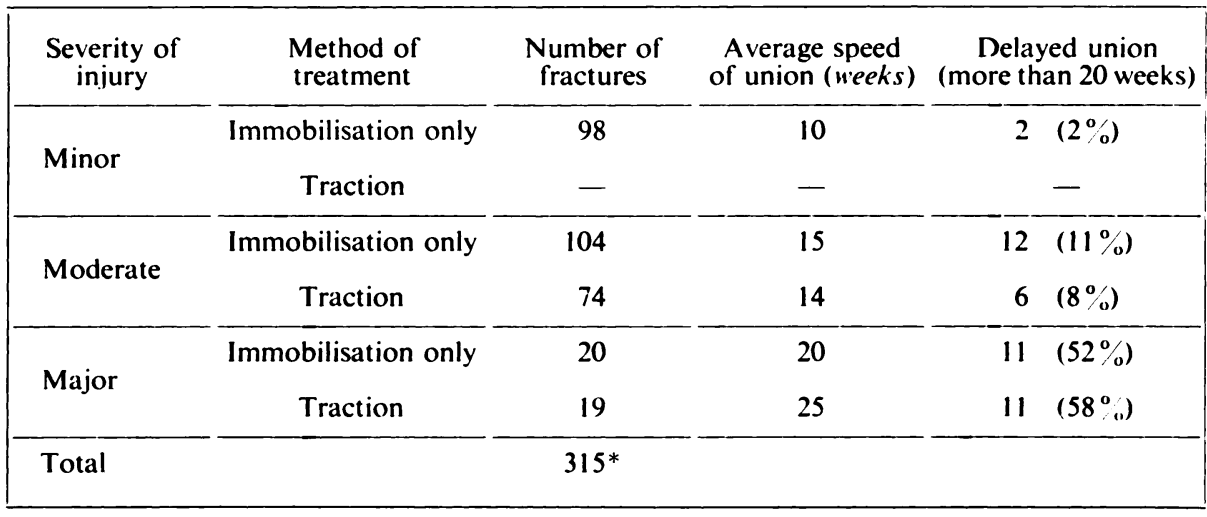

* Excludes eighteen distracted fractures.

\section{DISCUSSION}

The severity of injury-Several authors have suggested that the severity of injury is an important determinant of the speed of fracture healing (Carpenter, Dobbie and Siewers 1952, Griffiths 1942, Starr 1947, Wilson 1942). This suggestion has been confirmed and extended in the present investigation.

Although minor degrees of comminution or compound wounding had no effect on the speed of fracture healing in the cases that I studied, these complications become of considerable importance when they indicate, by their severity, that extensive tissue damage has taken place. As a third guide to the extent of the injury we have found complete displacement of the fragments also to be of importance. This relationship between the extent of the injury and the speed of bone union exists even when other factors, such as the method of treatment employed, are taken into consideration. In the present study it proved to be the most important single factor determining rate of fracture union. No investigation of other variables or comparison of results of different techniques of treatment can be considered valid unless the severity of the initial injury is taken into consideration.

The effects of traction and distraction on speed of union-Skeletal traction is frequently condemned because of its alleged retarding effect on the speed of fracture union. Albert (1944) and Watson-Jones and Coltart (1943), in studies of tibial fractures collected from a number of different centres, found that those treated by simple immobilisation united, on the average, more rapidly than those treated by skeletal traction, and they attributed this difference to 
the effects of the traction. However, many surgeons reserve skeletal traction for cases of severe comminution or extensive compound wounding (Sherman 1940, Venable and Stuck 1947). Without allowing for possible variations in the severity of injury between the two groups, no firm conclusion can be derived from any differences that may be found in their average speed of union.

There seems to be no doubt, from our own study, that delay in healing takes place if traction causes distraction of the bone ends. If distraction is avoided, however, the union of fractures of moderate severity appears to be unaffected by traction. Here our results are at variance with the controlled study of closed tibial fractures reported by Landoff in 1948. In severe fractures we found the average time of union somewhat longer in cases subjected to traction, although there was no increase in the incidence of delayed union or non-union.

It may be concluded from this study that should skeletal traction be indicated in a particular fracture it may be used without risk of precipitating serious delay in healing, provided distraction is avoided.

\section{SUMMARY}

1. A series of 343 tibial shaft fractures proceeding to sound union in adults, and 192 fractures in children, was studied. Groups of fractures differing from each other only in the one particular variable under consideration were compared.

2. The severity of the injury (as assessed by the degree of displacement, of comminution and of compound wounding) was found to be an important determinant of speed of fracture union and of incidence of delayed and non-union. A simple classification of severity of injury is described.

3. Distraction delayed healing. Traction which avoided distraction had no effect on the rate of union of fractures of moderate severity compared with cases of similar severity of injury treated by immobilisation only. Major fractures subjected to traction did take longer to unite on the average, but there was no increase in the incidence of delayed or non-union.

I would like to thank Mr F. W. Holdsworth for permission to examine the patients in this study, all of whom were under his care, and also for his advice and interest during the preparation of this paper. Dr C. W. Wilson kindly confirmed the statistical significance of the figures used in constructing the tables.

\section{REFERENCES}

AlBerT, M. (1944): Delayed Union in Fractures of the Tibia and Fibula. Journal of Bone and Joint Surgery, 26, 566.

Carpenter, E. B., Dobbie, J. J., and Siewers, C. F. (1952): Fractures of the Shaft of the Tibia and Fibula. Archives of Surgery, 64, 443.

Eluıs, H. (1956): A Study of Some Factors Affecting Prognosis Following Tibial Shaft Fractures. Thesis, Bodleian Library, Oxford.

GRIFFITHS, D. Ll. (1942): Delayed Union of Fractures. Lancet, ii, 10.

LANDOFf, G. A. (1948): A Comparative Study of Methods of Treatment of Diaphyseal Fractures of the Leg. Acta Orthopaedica Scandinavica, 18, 37.

Sherman, W. O. (1940): Treatment of Compound Fractures. Archives of Surgery, 40, 838.

StaRR, K. W. (1947): The Causation and Treatment of Delayed Union in Fractures. London: Butterworth \& Co. (Publishers) Ltd.

Venable, C. S., and Stuck, W. G. (1947): The Internal Fixation of Fractures. Oxford: Blackwell Scientific Publications Ltd.

Watson-Jones, R., and Coltart, W. D. (1943): Slow Union of Fractures. British Journal of Surgery, 30, 260. WILSON, H. (1942): Delayed Union of Fractures. Lancet, ii, 9. 